\title{
RAPID PRODUCTION OF SINGLE CRYSTALS OF IGE
}

\author{
By D. v.D. S. Roos \\ (National Physical Research Laboratory, C.S.I.R., Pretoria, South Africa)
}

\begin{abstract}
This paper describes how to grow single crystals of ice of desired orientation by applying the method of seed extraction from the melt. A single crystal of more than $\mathrm{I} g$ can be grown in less than one hour.

RÉsumé. Production rapide de monocristaux de glace. Cet article décrit un procédé de production rapide de monocristaux de glace, avec l'orientation désirée. La technique utilisée consiste à extraire progressivement le germe cristallin de la phase liquide. Un monocristal de plus de I g peut être obtenu en moins d'une heure.

Zusammenfassung. Schnelles Züchten von Eismonokristallen. Es wird eine Methode zum Züchten von Eismonokristallen gewünschter Orientierung durch Anwendung der Technik der Kristallkeimextraktion aus der Schmelze beschrieben. Ein Monokristall von mehr als $1 \mathrm{~g}$ kann in weniger als einer Stunde aufwachsen.
\end{abstract}

\section{INTRODUGTION}

Single crystals of ice are on occasions required for laboratory experiments. For example, Hallett ( 1964 ) used single crystals to investigate the freezing behaviour of impinging water droplets, Knight and Knight (1965) used them to grow "negative" ice crystals and Davy and Somorjai (I97I) studied the vaporization mechanism of ice single crystals. Hallett grew his single crystals by the method of grain competition, while the Knights made use of single crystals from a glacier. Davy and Somorjai employed the Kyropoulos method (Kyropoulos, I930; Adams and Lewis, I934; Jona and Scherrer, I952) in which heat is removed from a seed in contact with its melt. The present paper describes some simplifying modifications to the Kyropoulos method.

\section{Technique}

The following stages of the experiment may be distinguished:

\section{The seed}

A free-growing ice dendrite, its arms extending in the (OoOI) plane and propagating in the $\langle\mathbf{I} \mathbf{I} \overline{2} 0\rangle$ directions (Lindenmeyer and Chalmers, I966), was chosen as seed. Not only is the crystallographic orientation of the subsequent single crystal then known in advance, but also it is straightforward to obtain such a seed. Slightly supercooled distilled water was nucleated and after dendrites had formed, the remaining liquid was poured off. A crystal in which the dendrite arms had almost grown together into a flat platelet, usually thinner than $0.4 \mathrm{~mm}$, was then fractured to yield a piece of at least $5 \mathrm{~mm}$ in length (Fig. I).

\section{The melt}

Unboiled distilled water kept at a temperature of about $\mathrm{I}^{\circ} \mathrm{C}$ by means of a surrounding mixture of ice and water was used as melt. The container was placed on a platform with fine controllable height adjustment. During the experiment, the melt was agitated with a stirrer operating at I 400 r.p.m. to ensure the formation of a crystal free from visible air bubbles. This precaution prevented the zone ahead of the advancing ice-water interface from becoming supersaturated with dissolved air (Carte, 196I) and proved more effective for eliminating 


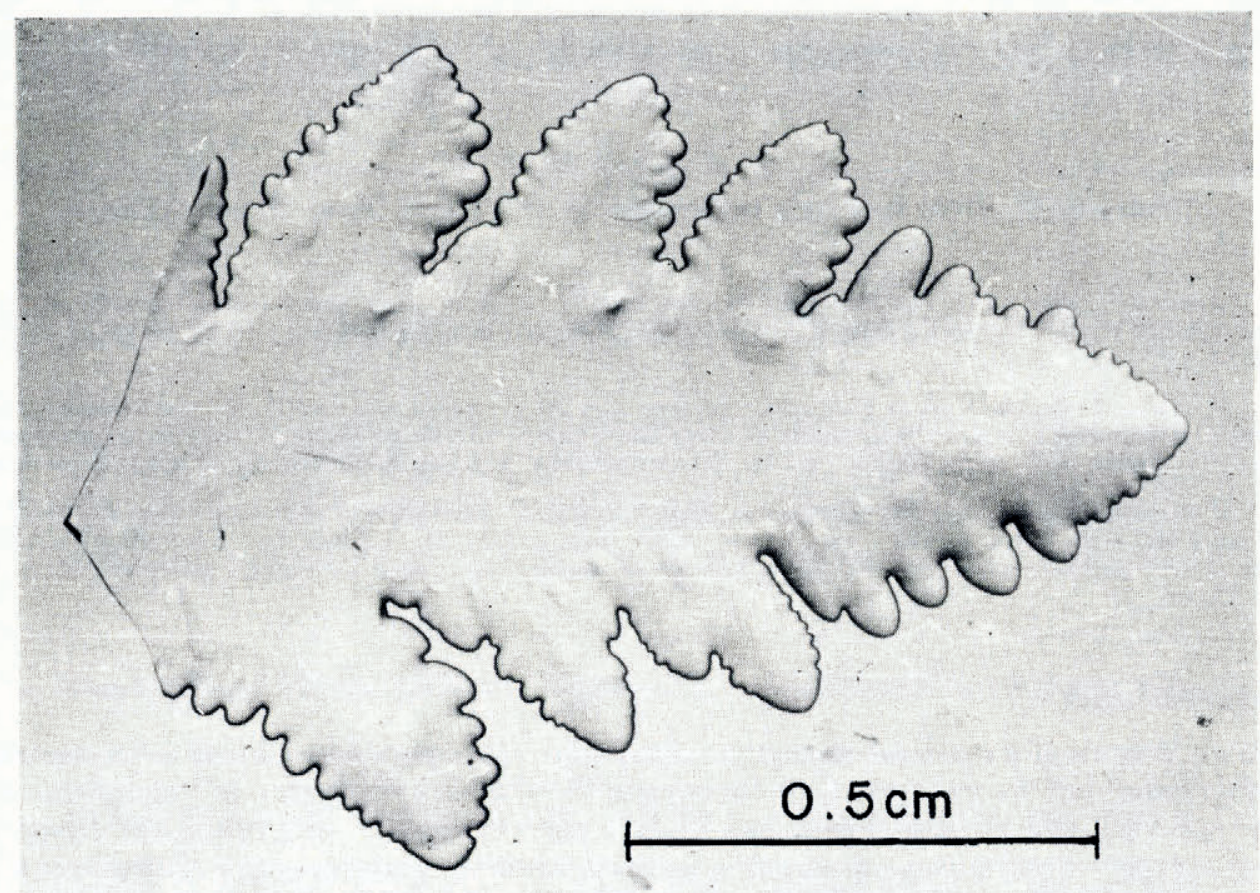

Fig. I. Plan view of a seed crystal with a mass of about $5 \mathrm{mg}$, having its optic axis normal to the plane of the figure. The primary arm (extending from left to right) and the secondary arms indicate the $\left\langle I^{I} \overline{2} O\right\rangle$ directions.

bubbles than pre-boiling the water. Also, stirring opposed the build-up of temperature gradients and thus prevented the formation of "parasitic crystals" (encountered by Adams and Lewis, 1934) on the surface of the melt.

\section{The single crystal}

A thermoelectric cooler, operating at a surface temperature of about $-14^{\circ} \mathrm{C}$ in air of $20^{\circ} \mathrm{C}$, was used as heat sink (see Fig. 2). The fragile seed, on a small heat insulator in a "deep freeze", had to be slightly melted on its top surface by a stream of warm air before the edge of the cooler base was rapidly frozen onto the centre of the seed. Growth was initiated by carefully raising the melt until contact was just made between its surface and the horizontally oriented seed. (When the seed was frozen flat against the cooler with its base oriented horizontally, inevitable contact between melt and cooler ruined the experiment). Stirring was commenced after lowering the melt by at least $1.5 \mathrm{~mm}$, because then the rippling liquid surface stayed clear from the cooler while cohesion was sustained between melt and crystal.

This specific arrangement resulted in a single crystal with a vertically directed $c$-axis and $a$-axes of known orientation. The ultimate size and shape of the single crystal were regulated by growth time and whether or not the growing crystal was extracted from the melt.

\section{Results}

A brilliant ice dome formed when growth took place under static conditions, i.e. when the seed was not extracted from the melt. An example is shown in Figure 3 (left-hand specimen). This crystal attained a mass of $0.8 \mathrm{~g}$ (equivalent spherical diameter of about $12 \mathrm{~mm}$ ) within 


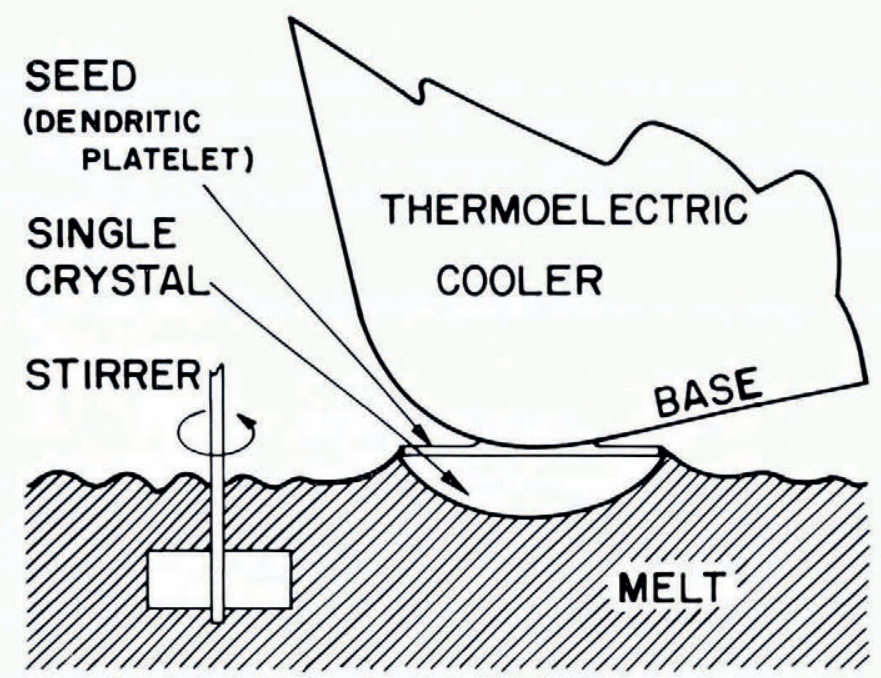

Fig. 2. Diagrammatic presentation of the growth of a single crystal of ice.

$20 \mathrm{~min}$. The shape of the single crystal became cylindrical when the level of the melt was lowered (or the crystal was extracted) at a suitable rate. Figure 3 (right-hand specimen) shows an extracted crystal which attained $0.4 \mathrm{~g}$ within $\mathrm{I} 6 \mathrm{~min}$ of growth. For the first $4 \mathrm{~min}$, however, growth was allowed under static conditions to ensure the required horizontal development. The subsequent average extraction rate of $0.4 \mathrm{~mm} \mathrm{~min}^{-1}$ was slightly too slow to produce a perfect cylinder. For given temperatures of cooler and melt, the rate of mass increase depended on the extraction rate and on the area of contact between crystal and cooler.

Viewing of a specimen between crossed polarizing filters showed that it was monocrystalline while the uniform shading for a certain orientation indicated little, if any, internal stress. Also, when the basal planes of specimens were smoothed by microtome and replicated in "Formvar" (polyvinyl formal) using first a $\frac{1}{2} \%$ and finally a $3 \%$ solution in ethylene dichloride, identically oriented hexagonal etch pits abounded but grain boundaries or subgrains were not found. The single crystals were evidently of high quality.

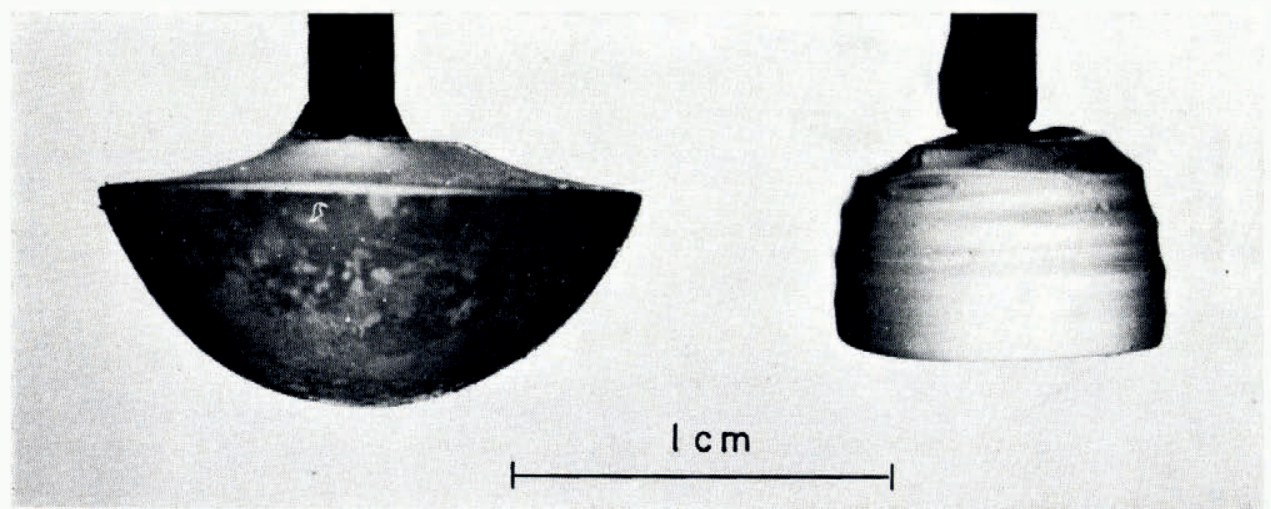

Fig. 3. Side view of single crystals that grew from seeds at their tops. The optic axes lay in the plane of the figure, parallel to the side of the page. The dome (left) grew in 20 min under static conditions while the specimen on the right was extracted from the melt over a period of $16 \mathrm{~min}$. 


\section{Conclusion}

The technique described above is recommended for producing single crystals of ice, especially when many of them are needed. It yields crystals of preselected orientation, it is quick (taking approximately as many minutes as the method of grain competition takes hours), it allows a certain amount of control over the final shape of the crystal and it proved to be highly reliable.

MS. received 28 June 1974 and in revised form ${ }_{3} 3$ September 1974

\section{REFERENGES}

Adams, J. M., and Lewis, W. 1934. The production of large single crystals of ice. Review of Scientific Instruments, New Series, Vol. 5, No. i i, p. 400-02.

Carte, A. E. 196r. Air bubbles in ice. Proceedings of the Physical Society (London), Vol. 77, No. 495, p. $757-68$.

Davy, J. G., and Somorjai, G. A. 1971. Studies of the vaporization mechanism of ice single crystals. Fournal of Chemical Physics, Vol. 55 , No. 8, p. 3624-36.

Hallett, J. 1964. Experimental studies of the crystallization of supercooled water. Fournal of the Atmospheric Sciences, Vol. 2 I, No. 6, p. $67 \mathrm{r}-82$.

Jona, F., and Scherrer, P. 1952. Die elastischen Konstanten von Eis-Einkristallen. Helvetica Physica Acta, Vol. 25, Fasc. 1-2, p. 35-54.

Knight, C. A., and Knight, N. C. 1965. "Negative" crystals in ice: a method for growth. Science, Vol, 150, No. 3705 , p. $1819-21$.

Kyropoulos, S. 1930. Dielektrizitätskonstanten regulärer Kristalle. Zeitschrift für Physik, Bd. 63, Ht. I1-12, p. 849-54.

Lindenmeyer, C. S., and Chalmers, B. 1966. Morphology of ice dendrites. Journal of Chemical Physics, Vol. 45, No. 8, p. 2804-06. 